\title{
Starch-lignin foams
}

\author{
E. S. Stevens ${ }^{1 *}$, A. Klamczynski², G. M. Glenn ${ }^{2}$ \\ ${ }^{1}$ Department of Chemistry, State University of New York at Binghamton, Binghamton, NY 13902, USA \\ ${ }^{2}$ Western Regional Research Center, Agricultural Research Service, United States Department of Agriculture, \\ 800 Buchanan Street, Albany, CA 94710, USA
}

Received 29 January 2010; accepted in revised form 18 March 2010

\begin{abstract}
Although starch foams are well known as biodegradable alternatives to foamed polystyrene, starch-lignin foams have not previously been reported. Lignin is an abundant byproduct of paper manufacture usually burned as fuel for lack of higher-value uses. We have prepared novel starch-kraft lignin foams with a known technique similar to compression molding. Replacing $20 \%$ of the starch with lignin has no deleterious effect on density or morphology as indicated by scanning electron microscopy: a thin outer layer of approximately $100 \mu \mathrm{m}$ encloses a region of cellular structure containing 100-200 $\mu \mathrm{m}$ voids, with the major internal region of the foam consisting of large voids of up to $1 \mathrm{~mm}$ in size. Powder X-ray diffraction shows residual structure in both starch and starch-lignin foams. Differential scanning calorimetry displays endothermic transitions in the starch foam but not in the starch-lignin foam, indicating that lignin stabilizes the residual starch structure. Lignin decreases water absorption; diffusion constants for the starch and starch-lignin foams are $2.68 \cdot 10^{-6}$ and $0.80 \cdot 10^{-6} \mathrm{~cm}^{2} / \mathrm{sec}$, respectively. The flexural strength of the starch-lignin foam is similar to that of foamed polystyrene, the strain at maximum stress is smaller, and the modulus of elasticity is larger.
\end{abstract}

Keywords: biopolymers, biodegradable polymers, starch, lignin, water absorption

\section{Introduction}

Biodegradable plastics made from renewable resources have received increased attention from polymer scientists, plastics manufacturers, and government agencies [1,2]. The driving force for this interest derives from sustainability gains and environmental amelioration provided through a reduced dependence on petroleum reserves, increased disposal options, and lower levels of greenhouse gases. This development has accrued in spite of acknowledged challenges connected with material properties, recycling, and cost [3-5]. Most of the interest in biodegradable plastics is aimed at developing low cost composites that are economical in high-volume applications. Applications considered most relevant include packaging and consumer products.
Starch-based materials have been of particular interest [6-10] because of the generally low cost of starch, and because thermoplastic starch [6] can be processed with conventional means such as extrusion and injection molding.

Starch foams are one segment of starch-based materials. Interest in foams is based on their low density, relative to non-foamed materials, which leads to lower material costs. Also, starch foams are biodegradable, in contrast to foamed polystyrene which is recalcitrant. Starch foams have been produced by extrusion [11-14], solvent exchange [15], and molding by means of a compression/explosion process [16].

Starch foams can also be produced with a technique similar to compression molding, whereby a mixture of starch, water, and additives is deposited into 
heated molds [17]. Excess water is vented as steam as the mixture expands and fills the mold cavity. A small amount of the mixture tends to be forced through the vents, which builds pressure inside the mold and produces foaming $[17,18]$. The properties of these foams and their dependence on composition and processing have been studied [18-21], largely with the aim of improving mechanical properties and moisture resistance.

There is also growing interest in lignin-based materials. Lignin is an abundant renewable natural resource. A byproduct of paper manufacture, lignin is considered a fairly intractable waste material and is usually burned as fuel for lack of higher-value uses. The properties and uses of lignin have recently been reviewed [22, 23]. Kumar et al. [24] have reviewed applications of lignin combined with other polymers.

Baumberger [25] has reviewed applications of lignin specifically in starch-lignin films. Stevens et al. [26] have examined thermoplastic starch-kraft lignin-glycerol blends prepared by film casting and by extrusion in a twin-screw extruder. Lignin is also produced as a byproduct in the refining process by which cellulose is isolated from lignocellulosic feedstocks. Starch-lignin materials can therefore be envisioned as becoming integrated into the production of bioethanol.

Starch-lignin foams have not previously been examined. The purpose of this study was to prepare and characterize starch-kraft lignin foams. The major applications for starch-lignin foams would be packaging containers for single or short-term use, as biodegradable alternatives to foamed polystyrene. Here the questions of interest were whether the presence of a significant amount of lignin would prevent foam formation or have any effect on water resistance and mechanical properties relative to starch foams.

\section{Materials and sample preparation}

Melojel cornstarch was purchased from National Starch and Chemical Company, Bridgewater, New Jersey. Indulin AT lignin (kraft pine lignin) was donated by MeadWestvaco, Charleston, South Carolina. Ammonium hydroxide (30\% aqueous solution) was purchased from Fisher Scientific Company. Magnesium stearate was purchased from Aldrich Chemical Company.

Sample compositions are shown in Table 1. The water content of the starch, measured by heating at $130^{\circ} \mathrm{C}$ for $1 \mathrm{~h}$ and weighing at $20^{\circ} \mathrm{C}$, was $11.6 \pm 0.1 \%$. Sample 1 was a control, with a weight ratio of starch (dry weight) to water (total weight) equal to 1.00. In samples 2 and 3, 10 and 20\% of the starch, respectively, was replaced with lignin. Water was added in an amount which kept the ratio of starch-plus-lignin to water equal to 1.00. Magnesium stearate was added as a release agent, at a level of $2.0 \%$ of the starch dry weight [19].

Lignin is soluble in aqueous solution only at high pH. In studies of starch-lignin cast films [26], ammonium hydroxide was used to raise the $\mathrm{pH}$ of the casting solution and was found to be a requirement for obtaining viable films. Preparing starchlignin films by extrusion, on the other hand, had no significant high-pH requirement [26]. In the present study, samples were prepared both with and without ammonium hydroxide. In samples $2 \mathrm{~N}$ and $3 \mathrm{~N}$, ammonium hydroxide was added as an aqueous solution (30\%) in an amount equal to the estimated stoichiometric amount of $\mathrm{OH}$ protons in pine kraft lignin [27], $2.0 \mathrm{ml}$ per $10 \mathrm{~g}$ lignin. The ammonium hydroxide is taken up by the starch-lignin mixture quickly so that after mixing there is no ammonia odor.

The dry ingredients were mixed manually. Water and, when used, ammonium hydroxide solution were added and the mixture again mixed manually. The mixture was placed in a $70^{\circ} \mathrm{C}$ water bath and

Table 1. Compositions

\begin{tabular}{|c|c|c|c|c|c|}
\hline Sample & Starch $^{\mathbf{a}}[\mathbf{g}]$ & Water $[\mathbf{g}]$ & Lignin $[\mathbf{g}]$ & $\mathbf{M g}_{\mathbf{4}} \mathbf{\text { stearate }}$ [g] & 2.96 \\
\hline 1 & 168 & 129 & 0 & 0 & 2.82 \\
\hline 2 & 160 & 137 & 14.16 & 2.70 \\
\hline 3 & 152 & 144 & 27.00 & 2.82 & 0 \\
\hline $3 \mathrm{~N}$ & 160 & 137 & 14.16 & 2.83 \\
\hline
\end{tabular}

aThe starch contained $11.6 \%$ water.

${ }^{b}$ Added as aqueous $\mathrm{NH}_{4} \mathrm{OH}$ solution (30\%) 
heated with mixing for 10-15 minutes after which time it had thickened to a doughlike consistency.

Foam samples were prepared in an oven (Hebenstreit GmbH, Model ZQe, Germany) with rectangular $6.5 \mathrm{~cm} \times 11.1 \mathrm{~cm}$ molds. The mold was preheated to $170^{\circ} \mathrm{C}$ and $30 \mathrm{~g}$ samples were heated for 50-60 s. The resulting foam panels were approximately $0.2 \mathrm{~cm}$ thick. After cooling, the panels were cut into strips $2.5 \mathrm{~cm} \times 16.5 \mathrm{~cm}$ for density, water absorption, and flexural measurements.

\section{Sample characterization 3.1. Morphology}

For density measurements, samples were conditioned for $48 \mathrm{~h}$ at $20^{\circ} \mathrm{C}$ and $50 \%$ relative humidity. Density was determined by weighing the foam and calculating the volume from measured dimensions. Four specimens of each sample were used.

For scanning electron microscope (SEM) measurements, specimens of samples 1 and $3 \mathrm{~N}$ were fractured in liquid nitrogen, dried, sputter-coated with Au-Pd, and examined with a Hitachi S-4700 scanning electron microscope.

For X-ray powder diffraction (XRD) analysis, specimens of samples 1 and $3 \mathrm{~N}$ were ground to a powder with a mortar and pestle. Analysis was carried out with a Philips X-pert PW3040 MPD diffractometer operated at $40 \mathrm{kV}$ and $20 \mathrm{~mA}$ using $\mathrm{CuK}_{\alpha}$ radiation with a graphite diffracted beam monochromator. Data were acquired in steps of $2 \theta=0.04^{\circ}$ and $4 \mathrm{~s}$.

\subsection{Differential scanning calorimetry (DSC)}

Foam samples were first ground into a fine powder with a mortar and pestle to improve thermal contact with the aluminum DSC cells. The heating curve of kraft lignin alone was also obtained. DSC measurements were made with a Perking Elmer Jade instrument calibrated with indium $(T, \Delta H)$ and zinc $(T)$. Samples (12.0-21.0 mg) were placed in cells and sealed at ambient temperature $\left(23 \pm 2^{\circ} \mathrm{C}\right)$ and relative humidity $(50 \pm 10 \%)$. Heating was from $30-130^{\circ} \mathrm{C}$ at $10^{\circ} \mathrm{C} / \mathrm{min}$. Measurements were made on 2-4 samples of each composition.

\subsection{Water absorption}

An immersion gravimetric method was used for measuring water absorption [28-30]. Specimens of samples 1 and $3 \mathrm{~N}, 7.6 \times 2.5 \times 0.2 \mathrm{~cm}$, were conditioned for $24 \mathrm{~h}$ at $50^{\circ} \mathrm{C}$, weighed, then immersed in a $23^{\circ} \mathrm{C}$ water bath for specified times of $15 \mathrm{sec}$ to $30 \mathrm{~min}$. The foams were held vertically under water by two wires penetrating the foam and attached to a clamp, thereby maximizing exposure to water. After immersion, excess water was removed with absorbent paper and the specimens were reweighed. Two-to-four specimens were measured for each sample at each immersion time.

The amount of water that entered the sample per unit surface area at time $t, m_{t}$, was calculated. Different specimens were used for each immersion time, so values of $m_{t}$ were normalized to a uniform sample weight $(0.727 \mathrm{~g})$, and divided by the surface area of a sample of that weight, calculated from the density measurements to be $35.4 \mathrm{~cm}^{2}$.

\subsection{Flexural properties}

Before mechanical testing, samples were conditioned for $24 \mathrm{~h}$ at a temperature of $23 \pm 2^{\circ} \mathrm{C}$ and relative humidity of 53\% using a saturated solution of $\mathrm{Mg}\left(\mathrm{NO}_{3}\right)_{2}$. Three-point flexural tests were carried out with an Instron Model 4500 testing machine according to ASTM Test Method D 790 [31]. Specimen width was $2.5 \mathrm{~cm}$, span setting was $10.0 \mathrm{~cm}$, and crosshead speed was $2.54 \mathrm{~mm} / \mathrm{min}$. The number of specimens of each sample was 6-8.

In this ASTM test method, flexural stress is calculated according to Equation (1):

$\sigma_{f}=\frac{3 P L}{2 b d^{2}}$

where $\sigma_{f}$ is the flexural stress at the midpoint of the specimen, in MPa; $P$ is the load at a given point on the load-deflection curve, in Newtons; $L$ is the support span, in $\mathrm{mm} ; b$ is the width of the specimen, in $\mathrm{mm}$; and $d$ is the thickness of the specimen, in $\mathrm{mm}$. For the specimens used here, $L=100 \mathrm{~mm}, b=$ $25.4 \mathrm{~mm}$, and $d$ varied within a range near $2.0 \mathrm{~mm}$. We report flexural strength, i.e., the maximum flexural stress, which uses the load $(P)$ at the maximum on the load-deflection curve; e.g., for $P=2.0 \mathrm{~N}$, $\sigma_{f}=3.0 \mathrm{MPa}$. 
Flexural strain is calculated according to Equation (2):

$\varepsilon_{f}=\frac{6 D d}{L^{2}}$

where $\varepsilon_{f}$ is the fractional change of an element of the outer surface of the specimen at the midpoint, in $\mathrm{mm} / \mathrm{mm} ; D$ is the maximum deflection of the center of the specimen, in $\mathrm{mm}$; and $L$ and $d$ are as in Equation (1). We report flexural strain at maximum flexural stress, as a percent, $\varepsilon_{f} 100$; e.g., for $D=$ $10 \mathrm{~mm}, \varepsilon_{f}=1.2 \%$.

The modulus of elasticity in bending is the ratio, within the elastic limit, of stress to corresponding strain, as in Equation (3):

$$
E_{b}=\frac{L^{3} m}{4 b d^{3}}
$$

where $E_{b}$ is the modulus of elasticity in bending, in $\mathrm{MPa} ; m$ is the slope of the tangent to the initial straight-line portion of the load-deflection curve, in $\mathrm{N} / \mathrm{mm}$ of deflection; and $L, b$, and $d$ are as in Equation (1).

\section{Results and discussion}

\subsection{Morphology}

Figure 1 shows optical scans of a starch and starchlignin foam. Lignin imparts a brown color.

Foam densities are shown in Table 2. The density of the control sample is the same as that previously reported [19] for a similarly processed foam having a $1: 1$ starch:water composition $\left(0.22 \mathrm{~g} / \mathrm{cm}^{3}\right)$. Foam density is known to depend on starch source, water content, heating temperature, and heating time $[18,19]$.

Lignin has little effect on foam density. The difference between samples $2 \mathrm{~N}$ and $3 \mathrm{~N}$ is only marginally significant but suggests that the effect of

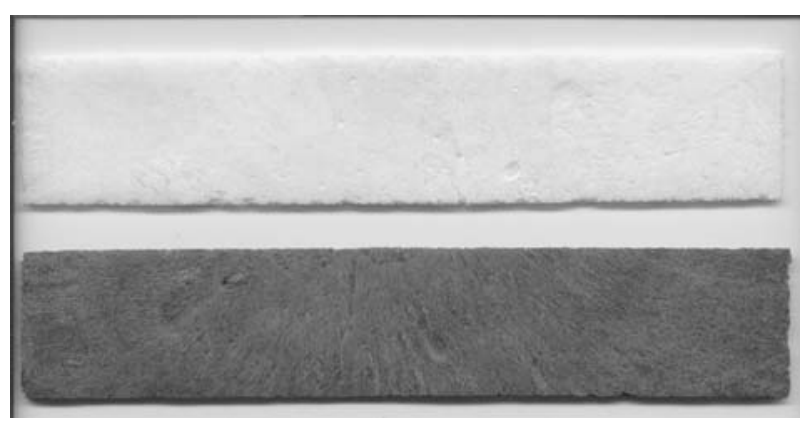

Figure 1. Optical scans of starch foam (top) and starchlignin foam (bottom)
Table 2. Sample densities ${ }^{\mathrm{a}}$

\begin{tabular}{|c|c|}
\hline Sample & Density $\left[\mathbf{g} / \mathbf{c m}^{\mathbf{3}}\right]$ \\
\hline 1 & $0.23 \pm 0.02$ \\
\hline 2 & $0.24 \pm 0.02$ \\
\hline 3 & $0.21 \pm 0.01$ \\
\hline $2 \mathrm{~N}$ & $0.31 \pm 0.07$ \\
\hline $3 \mathrm{~N}$ & $0.24 \pm 0.03$ \\
\hline
\end{tabular}

aAverage values \pm estimated standard deviation $(\mathrm{N}=4)$

ammonium hydroxide on density may depend on the amount of lignin present. For example, it may be that lignin has the effect of decreasing foam density, whereas ammonium hydroxide has the effect of increasing foam density.

Typical densities of foamed polystyrene are $0.06-0.09 \mathrm{~g} / \mathrm{cm}^{3}[16,18,19]$, less than what is observed here. However, starch foams prepared by extrusion [13] have densities of approximately $0.06-0.07 \mathrm{~g} / \mathrm{cm}^{3}$, similar to foamed polystyrene. Extrusion may lead to lower densities in starchlignin foams than foams obtained with the present method.

SEM images of samples 1 and $3 \mathrm{~N}$ are shown in Figure 2. The features of starch foams (Figure 2a) have been observed previously $[17,18]$. Below a thin surface 'skin' of approximately $100 \mu \mathrm{m}$ in thickness, there is a region of cellular structure containing $100-200 \mu \mathrm{m}$ voids. The major internal region of the foam consists of large voids of up to $1 \mathrm{~mm}$ in size. The boundaries separating these regions are not sharp, but the combined thickness of the outer skin and smaller voids in the present micrographs is approximately $0.045 \mathrm{~cm}$, similar to what has been observed previously $[17,18]$.

Starch-lignin foams display the same features (Figure 2b). Lack of contrast makes the location of the dispersed lignin impossible. Nevertheless, the SEM images show that $20 \%$ lignin can be incorporated into starch foams without collapse of the foam and with no major change in morphology.

Figures $2 \mathrm{c}$ and $2 \mathrm{~d}$ show enlarged images of samples 1 and $3 \mathrm{~N}$, respectively. The walls of the internal cells are approximately $10 \mu \mathrm{m}$ thick, whether or not the foams contain lignin.

Therefore, SEM indicates that replacing $20 \%$ of the starch with lignin has no deleterious effect on overall morphology.

$\mathrm{X}$-ray diffraction patterns of samples 1 and $3 \mathrm{~N}$ are shown in Figure 3. The significant diffraction maximum at $19.4^{\circ}$ and a weaker maximum at $12.7^{\circ}$ in both samples indicate the presence of residual 


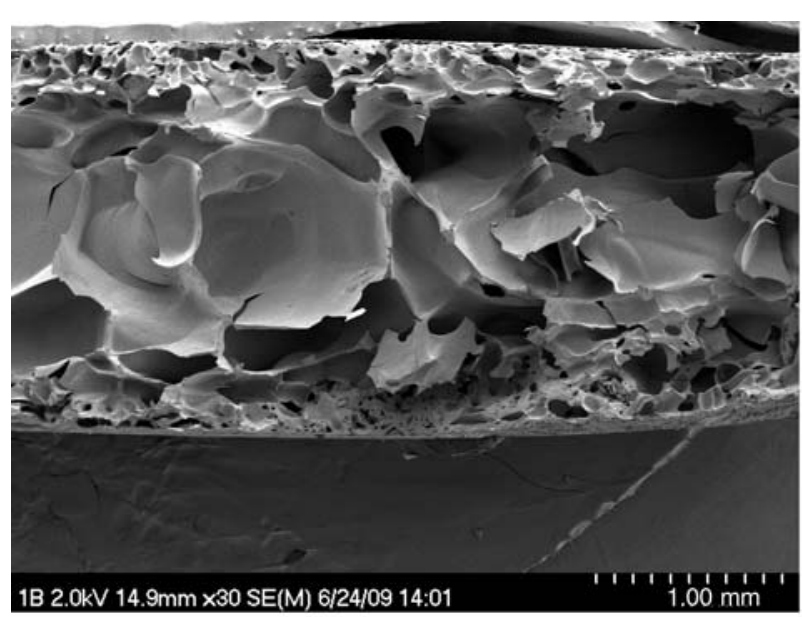

a)

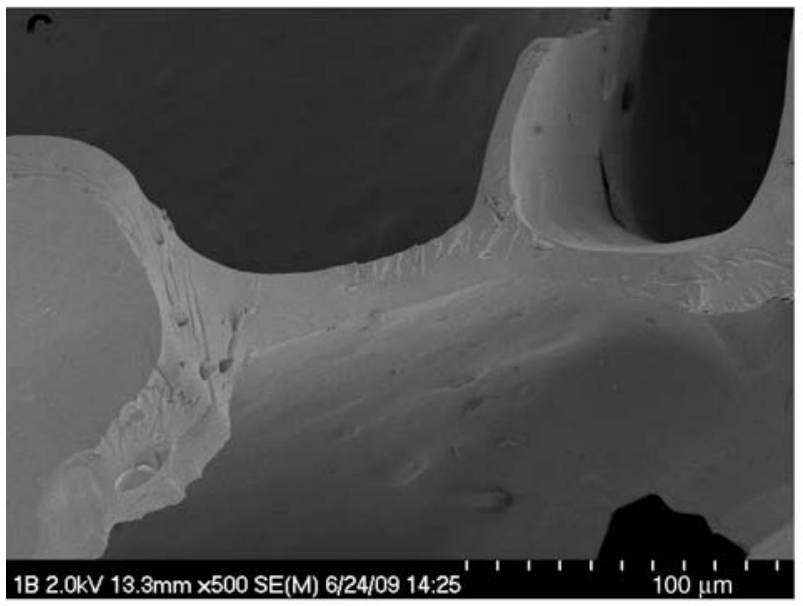

c)

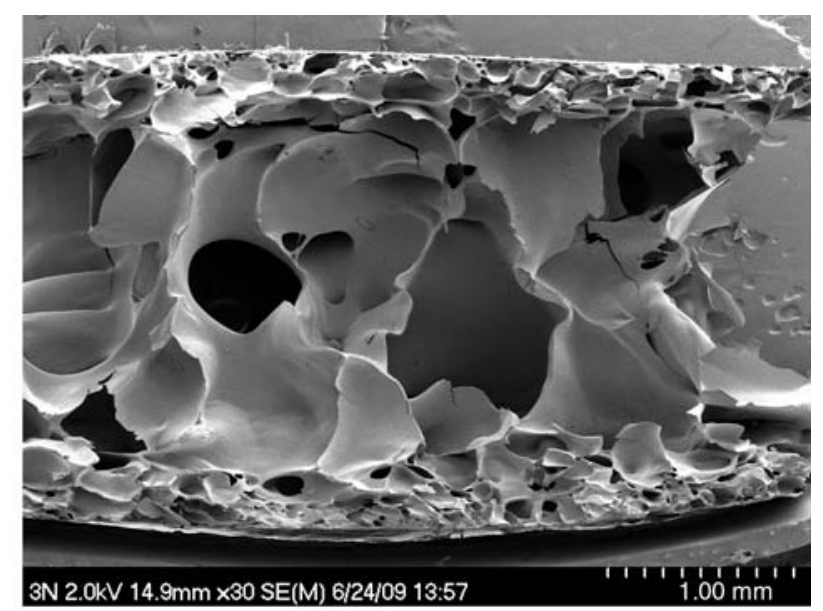

b)

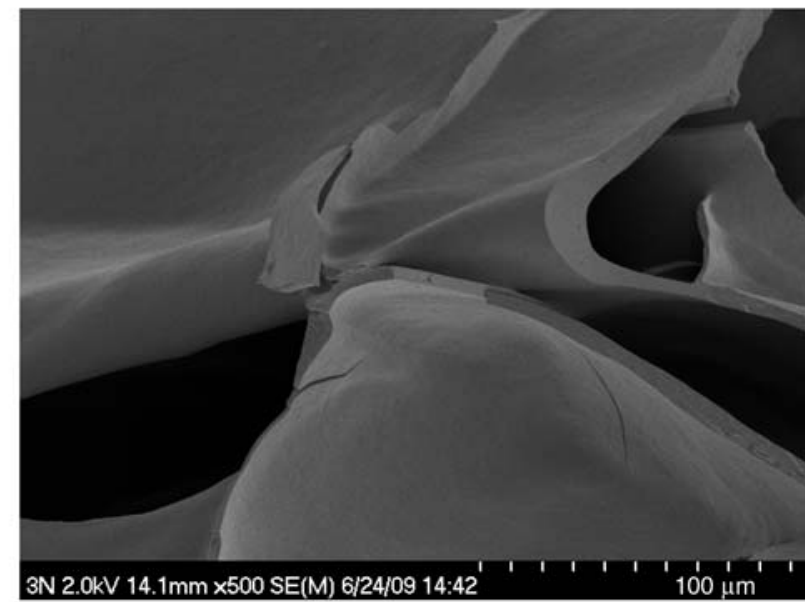

d)

Figure 2. SEM images of (a) starch (sample 1), (b) starch-lignin (sample 3N), (c) starch (sample 1), and (d) starch-lignin (sample $3 \mathrm{~N}$ )

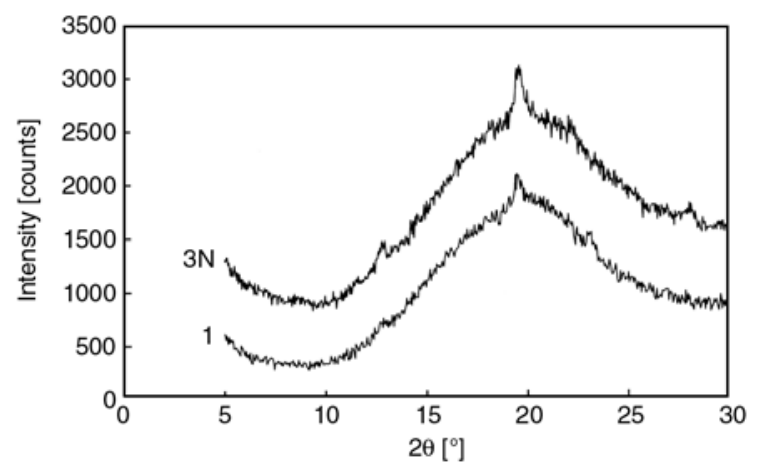

Figure 3. Powder X-ray diffraction patterns of foams of starch (sample 1) and starch-lignin (sample 3N)

structure of the $\mathrm{V}$ form of starch $[13,18,32]$. The absence of the B structure indicates that the native structure in the starch granule was destroyed during foam formation. Some of the amylose probably recrystallized into the $\mathrm{V}$ form during the cooling [32].

\subsection{Differential scanning calorimetry}

Figure 4 shows the heating curves of the five samples described in Table 1. The starch foam (curve 1) displays, within the measured temperature range, a broad endothermic peak and a second smaller feature. Peak temperatures, averaged over four specimens, were $85 \pm 1$ and $95 \pm 2^{\circ} \mathrm{C}$, respectively. The integrated area, including both features and averaged over four specimens, corresponds to $\Delta H=2.0 \pm 0.1 \mathrm{~J} / \mathrm{g}$ of dry starch.

DSC features observed with starch samples depend on water content, age, source plant, and sample history [32-34]. For our purposes, the thermal features in the starch foam (Figure 4, curve 1) need only be taken to indicate that heat treatment of starch during foam formation leaves some residual starch structure [32]. XRD analysis (above) indicates that structure to be the $\mathrm{V}$ form of amylose. 


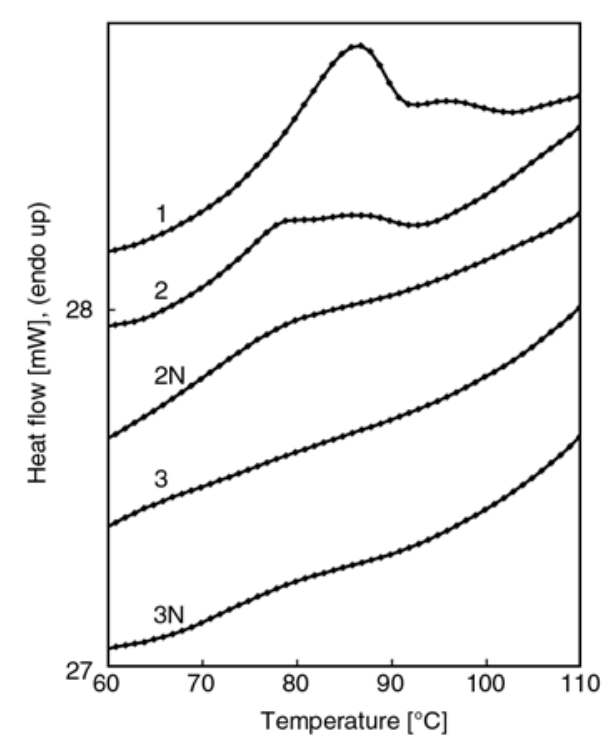

Figure 4. DSC curves for the samples described in

Table 1. The curves have been displaced on the vertical axis for ease in viewing.

Sample 2, containing 10\% lignin and prepared without ammonium hydroxide, similarly shows two thermal features but shifted to lower temperatures, approximately 78 and $86^{\circ} \mathrm{C}$, and with a decreased enthalpy change of $0.91 \pm 0.02 \mathrm{~J} / \mathrm{g}$ of starch. The remaining samples show no distinct thermal features ( $\Delta H \leq 0.3 \mathrm{~J} / \mathrm{g}$ of starch).

$\mathrm{X}$-ray diffraction analysis indicates the presence of residual structure in both samples 1 and $3 \mathrm{~N}$, but only sample 1 displays a thermal transition by DSC. This result indicates that, when lignin is present, starch-lignin interactions are sufficient to inhibit the thermal transition, as in sample $3 \mathrm{~N}$.

As a control experiment, the DSC of the lignin used in this work was measured (Figure 5). Upon first heating (curve a) there is a broad endothermic peak at $80 \pm 2^{\circ} \mathrm{C}$ with $\Delta H=5.7 \pm 0.6 \mathrm{~J} / \mathrm{g}$. After cooling and reheating (curve b) the same sample shows no

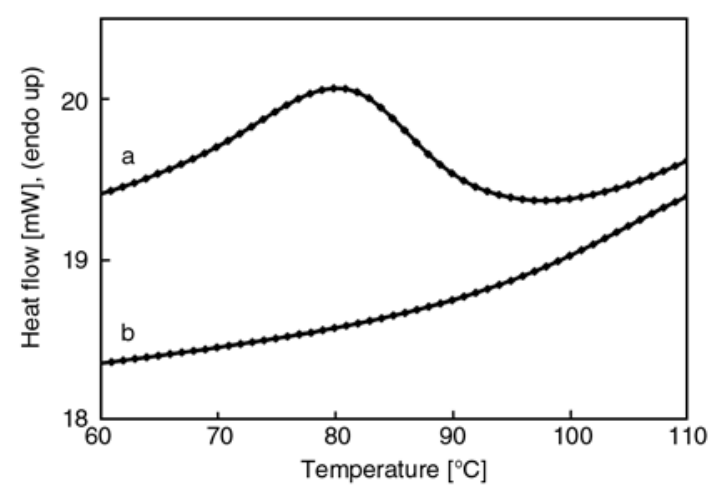

Figure 5. DSC curves for lignin; (a) first heating, (b) second heating. The curves have been displaced on the vertical axis for ease in viewing. thermal features in the temperature range examined here. Therefore, following foam formation, lignin does not contribute to the DSC data displayed in Figure 4.

The data also suggest that the effect of ammonium hydroxide on thermal features, as with its effect on foam density (above), depends on the amount of lignin present: at 10\% lignin the melting features are absent only when ammonium hydroxide is used, whereas at $20 \%$ lignin the melting features are absent whether or not ammonium hydroxide is used. This result could be a concentration dependent phenomenon related to the way in which lignin is dispersed throughout the foam.

A hypothesis for the action of ammonium hydroxide is that dissolution of lignin at high $\mathrm{pH}$ involves phenolate formation in the lignin component; the $p K_{a}$ of phenol is 9.9. Phenolate ions then interact with hydroxyl groups of the starch through iondipole interactions, supplementing hydrogen-bonding dipole-dipole interactions. Some ammonium ions remain as phenolate counterions and excess ammonia escapes during the mixing and heating processes. By the time the foams are formed, there is no free ammonia and no ammonia odor.

\subsection{Water absorption}

An empirical power law model has often been used to describe polymer absorption dynamics $[35,36]$ (Equation 4):

$m_{t}=k t^{n}$

where $m_{t}$ is the mass of absorbed water per unit area at time $t ; k$ is an empirical rate parameter proportional to $D^{1 / 2}$, where $D$ is the diffusion constant; and $n$ is a parameter related to the diffusion mechanism. When $n$ is equal to 0.5 the dynamics are referred to as Fickian $[29,30,35,36]$.

Figure 6 shows a plot of $m_{t}$ versus $t^{1 / 2}$ for samples 1 (starch) and 3N (starch-lignin), with $m_{t}$ in units of $\mathrm{g} / \mathrm{cm}^{2}$ and $t$ in seconds. The behavior is initially linear, but the slopes increase at longer times. The results of this empirical model indicate qualitatively that lignin impedes the absorption of water. The ratio of the limiting slopes, at short times, for samples 1 and $3 \mathrm{~N}$ is approximately 2:1, indicating a ratio of effective diffusion constants of approximately 4:1. This simple empirical model, however, provides little insight into the mechanism of diffu- 


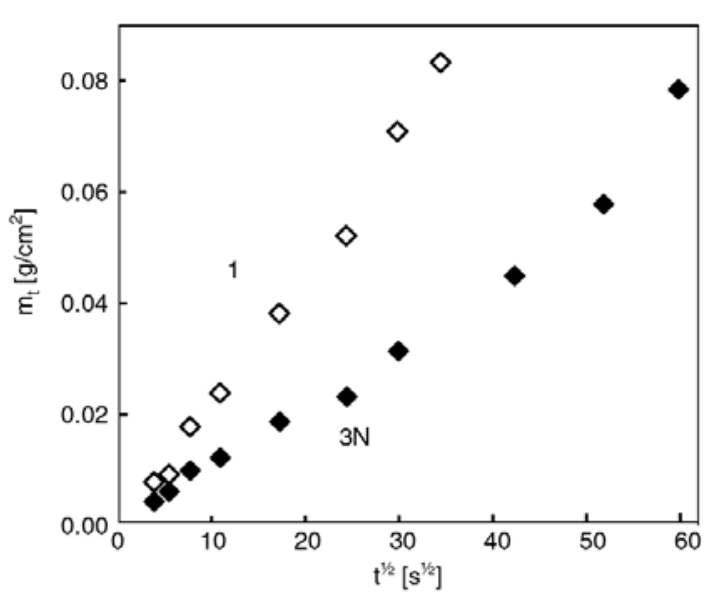

Figure. 6. Water absorption described by an empirical power law model (Equation 4). Sample 1, starch; sample 3N, starch-lignin.

sion and does not explain the departure from linearity in Figure 6 at long times.

Crank [37], on the other hand, provides a nonempirical, analytical solution to Fick's diffusion equations for boundary conditions appropriate to the present materials; i.e., diffusion into a slab having an outer layer of thickness, $l$, through which diffusion is determined by a diffusion constant, $D$. It is assumed that further movement of water into the core is unhindered.

The large voids in the present materials led us to examine that model. The specimens were cut from the original larger samples, exposing voids along the edges, but for the sample sizes used here, only $10 \%$ of the surface area was exposed.

In such a model, solutions to Fick's diffusion equations are obtained [37] as in Equation (5):

$$
\begin{aligned}
\frac{m_{t}}{2 l c_{0}} & =\left(\frac{D t}{l^{2}}\right)^{1 / 2} \frac{1}{\sqrt{\pi}}\left\{1+2 \sum_{n=1}^{\infty} \exp \left(-\frac{n^{2} l^{2}}{D t}\right)\right\} \\
& -2 \sum_{\mathrm{n}=1}^{\infty} n \operatorname{erfc}\left(\frac{n l}{\sqrt{\mathrm{Dt}}}\right)
\end{aligned}
$$

where $c_{0}$ is the water concentration at the surface, $1.00 \mathrm{~g} / \mathrm{cm}^{3}$, and erfc is the error function complement. The thickness of the outer region, $l$, was estimated from the SEM images (Figure 2) to be $0.045 \mathrm{~cm}$.

Equation (5) contains only the single fit parameter, $D$. Crank [37] points out that when $m_{t} / 2 l c_{0}$ is plotted as a function of $\left(D t / /^{2}\right)^{1 / 2}$, the curve is expected to be linear for small times but that its gradient later increases steadily as $t$ increases. When plotted as a function of $D t / l^{2}$ the curve is initially parabolic, then becomes linear. Data for samples conforming to the model will be superimposed, with data for different samples being distinguished by different values of the fitted parameter, $D$.

Data for each of samples 1 and $3 \mathrm{~N}$ were fit to Equation (5) by minimizing $\chi^{2}$. For sample 1 (starch), $D=2.68 \cdot 10^{-6} \mathrm{~cm}^{2} / \mathrm{sec}$, with a standard deviation for the fit of 0.036. For sample 3N (starch-lignin), $D=0.80 \cdot 10^{-6} \mathrm{~cm}^{2} / \mathrm{sec}$, with a standard deviation for the fit of 0.026 .

Figure 7 shows the present data plotted as a function of $\left(D t / l^{2}\right)^{1 / 2}$, displaying the expected initial linear behavior and significant curvature at longer times. Figure 8 shows the data plotted as a function of $D t / l^{2}$, displaying the initial parabolic behavior and the expected linear behavior at longer times.

Equation (5) accounts satisfactorily for the data of both samples. Lignin impedes diffusion into the outer layers of the foam but does not affect the diffusion mechanism. The ratio of the two effective diffusion constants is 3.4 , indicating a significant improvement in water resistance in the starchlignin foam.

Baumberger et al. [38], who studied starch-lignin films, also found that lignin improves water resistance, as long as no plasticizer is used. Stevens et al. [26] found that if glycerol is used to plasticize starch-lignin films, the effect of the glycerol is to reduce or eliminate the hydrophobic effect of lignin.

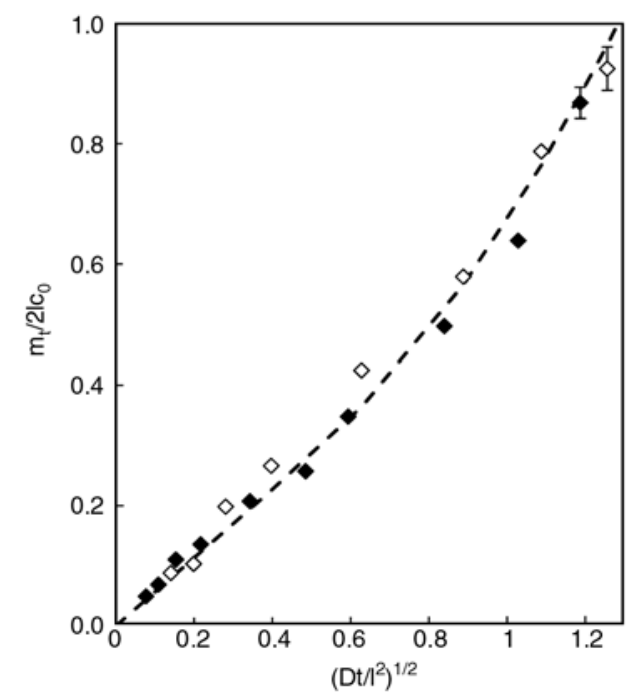

Figure 7. Water absorption as a function of $\left(D t / /^{2}\right)^{1 / 2}$ as described by Equation (5); $\diamond$, starch (sample 1); $\diamond$, starch-lignin (sample 3N). The dashed line represents the best fit to Equation (5); the error bars show the standard deviation of the fit. 


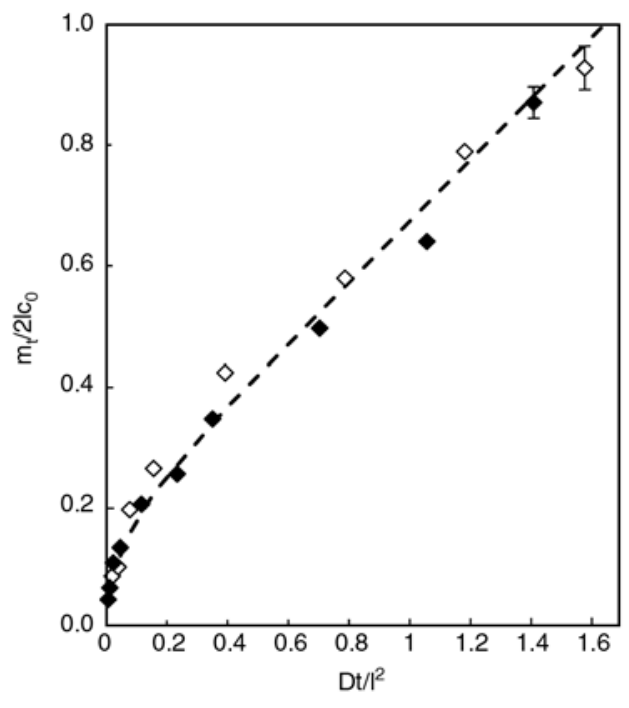

Figure 8. Water absorption as a function of $\left(D t / l^{2}\right)^{1 / 2}$ as described by Equation (5); $\diamond$, starch (sample 1); $\diamond$, starch-lignin (sample 3N). The dashed line represents the best fit to Equation (5); the error bars show the standard error of the fit.

\subsection{Flexural properties}

The load deflection curves for the starch control samples showed an increase in strain beyond the point of maximum stress; they showed a yield. Beyond the yield, there was an additional strain of approximately $0.2 \%$ before the sample broke. On the other hand, foams containing lignin displayed no yield; they broke at the maximum measured stress.

Flexural properties are shown in Table 3. Shogren et al. [39] and Lawton et al. [40] have shown that starch content, plant source, and moisture content affect the mechanical properties of foams prepared by the present method. Results for the control sample can be compared with reported values [19] representing averages for corn, wheat, potato and tapioca starch foams and prepared with a 1:1 starch: water composition: flexural strength, $4.7 \mathrm{MPa}$;

Table 3. Flexural properties ${ }^{\mathrm{a}}$

\begin{tabular}{|c|c|c|c|c|}
\hline Sample & $\mathbf{N}^{\mathbf{b}}$ & $\begin{array}{c}\text { Flexural } \\
\text { strength } \\
{[\mathrm{MPa}]}\end{array}$ & $\begin{array}{c}\text { Strain at } \\
\text { maximum } \\
\text { stress [\%] }\end{array}$ & $\begin{array}{c}\text { Modulus of } \\
\text { elasticity } \\
{[\mathrm{MPa}]}\end{array}$ \\
\hline 1 & 6 & $2.61 \pm 0.32$ & $1.4 \pm 0.1$ & $235 \pm 37$ \\
\hline 2 & 8 & $2.20 \pm 0.28$ & $0.7 \pm 0.1$ & $348 \pm 24$ \\
\hline 3 & 8 & $2.44 \pm 0.30$ & $0.6 \pm 0.1$ & $395 \pm 32$ \\
\hline $2 \mathrm{~N}$ & 8 & $2.71 \pm 0.55$ & $0.7 \pm 0.4$ & $518 \pm 149$ \\
\hline $3 \mathrm{~N}$ & 7 & $1.56 \pm 0.56$ & $0.6 \pm 0.2$ & $296 \pm 55$ \\
\hline
\end{tabular}

aAverage values \pm estimated standard deviation.

bNumber of specimens. strain at maximum stress, $2.2 \%$; modulus of elasticity, $281 \mathrm{MPa}$.

Foams with $10 \%$ lignin or $20 \%$ lignin, prepared without ammonium hydroxide (samples 2 and 3), displayed the same flexural strength as the starch control, a decreased strain at maximum stress, and a larger modulus of elasticity.

Foams with $10 \%$ lignin, prepared with ammonium hydroxide (sample $2 \mathrm{~N}$ ), displayed the same flexural strength and strain at maximum stress as foams prepared without ammonium hydroxide, but a larger modulus of elasticity; the increase in modulus between samples 2 and $2 \mathrm{~N}$ is significant at the 99\% confidence level.

In foams with $20 \%$ lignin and prepared with ammonium hydroxide (sample $3 \mathrm{~N}$ ), the ammonium hydroxide had the effect of significantly decreasing flexural strength ( $99 \%$ confidence level), but had no further effect on strain at maximum stress. The modulus of elasticity decreased relative to the other lignin-containing samples, but was larger than the value for the starch control (95\% confidence level). Thus, the effect of ammonium hydroxide appears to depend on the amount of lignin present.

The present results can be compared with those of Baumberger et al. [38] who prepared starch-kraft lignin pre-extruded molded films containing only water as a plasticizer. They observed tensile elongations at break of $1.0-1.5 \%$. Without additional plasticization, lignin increases the brittleness of both films and foams.

For comparison, the values for foamed polystyrene are: flexural strength, $1.3 \mathrm{MPa}$; strain at maximum stress, 1.7\%; and modulus of elasticity, $105 \mathrm{MPa}$ [19]. The flexural strength of starch-kraft lignin foams is, therefore, similar to that of foamed polystyrene; the strain at maximum stress is smaller, and the modulus of elasticity is larger.

Starch foams have also been produced by extrusion and other means [11-16], and the mechanical and other properties of starch-lignin foams are likely to depend on processing.

\section{Conclusions}

Replacing $20 \%$ of the starch with lignin does not prevent foam formation and has no deleterious effect on foam density or morphology. Lignin significantly decreases the rate of water absorption. 
XRD and DSC together indicate that there are significant starch-lignin interactions that stabilize residual structure in the starch. Starch-lignin foams prepared by the present method have approximately the same flexural strength as foamed polystyrene, a smaller strain at maximum stress, and a larger modulus of elasticity.

\section{Acknowledgements}

We thank MeadWestvaco for donations of Indulin AT. The technical assistance of Tina Williams, Marie Cope, and David M. Jenkins is gratefully acknowledged.

\section{References}

[1] Chiellini E., Solaro R.: Biodegradable polymers and plastics. Plenum Press, New York (2003).

[2] Wool R. P., Sun X. S.: Bio-based polymers and composites. Elsevier, Amsterdam (2005).

[3] Zhang M. Q.: Polymeric materials from natural resources- Emerging as the times require. Express Polymer Letters, 1, 406 (2007).

DOI: $10.3144 /$ expresspolymlett.2007.57

[4] Krawczak P.: Plastics and composites based on renewable resources: End-of-life recycling and recovery issues. Express Polymer Letters, 2, 237 (2008). DOI: $10.3144 /$ expresspolymlett.2008.28

[5] Karger-Kocsis J.: Thermoset polymers containing biobased renewable resources. Express Polymer Letters, 3, 676 (2009).

DOI: 10.3144/expresspolymlett.2009.84

[6] Avérous L.: Biodegradable multiphase systems based on plasticized starch: A review. Journal of Macromolecular Science Polymer Reviews, 44, 231-274 (2004). DOI: $10.1081 / \mathrm{mc}-200029326$

[7] Tábi T., Kovács J. G.: Examination of injection moulded thermoplastic maize starch. Express Polymer Letters, 1, 804-809 (2007). DOI: $10.3144 /$ expresspolymlett.2007.111

[8] Cao X., Chen Y., Chang P. R., Muir A. D., Falk G.: Starch-based nanocomposites reinforced with flax cellulose nanocrystals. Express Polymer Letters, 2, 502510 (2008) DOI: $\underline{10.3144 / \text { expresspolymlett.2008.60 }}$

[9] Wittek T., Tanimoto T.: Mechanical properties and fire retardancy of bidirectional reinforced composite based on biodegradable starch resin and basalt fibres. Express Polymer Letters, 2, 810-822 (2008). DOI: 10.3144/expresspolymlett.2008.94

[10] Lu D. R., Xiao C. M., Xu S. J.: Starch-based completely biodegradable polymer materials. Express Polymer Letters, 3, 366-375 (2009).

DOI: 10.3144/expresspolymlett.2009.46
[11] Lacourse N. L., Altieri P. A.: Biodegradable packaging material and the method of preparation thereof. U. S. Patent 4863655, USA (1989).

[12] Harper J. M., Tribelhorn R. E.: Expansion of native cereal starch extrudates. in 'Food extrusion science and technology' (eds.: Kokini J. L., Ho C., Karwe M. V.) Marcel Dekker, New York, 653-667 (1992).

[13] Willett J. L., Shogren R. L.: Processing and properties of extruded starch/polymer foams. Polymer 43, 59355947 (2002).

DOI: $\underline{10.1016 / \mathrm{S} 0032-3861(02) 00497-4}$

[14] Glenn G., Klamczynski A., Holtman K. M., Chiou B-S., Orts W. J., Wood D.: Cellulose fiber reinforced starch-based foam compositions. Journal of Biobased Materials and Bioenergy, 1, 360-366 (2007). DOI: $10.1166 / \mathrm{jbmb} .2007 .010$

[15] Glenn G. M., Irving D. W.: Starch-based microcellular foams. Cereal Chemistry, 72, 155-161 (1995).

[16] Glenn G. M., Orts W. J.: Properties of starch-based foam formed by compression/explosion processing. Industrial Crops and Products, 13, 135-143 (2001). DOI: $10.1016 / \mathrm{S} 0926-6690(00) 00060-1$

[17] Tiefenbacher K. F.: Starch-based foamed materials Use and degradation properties. Journal of Macromolecular Science, Pure and Applied Chemistry A, 30, 727-731 (1993).

[18] Shogren R. L., Lawton J. W., Doane W. M., Tiefenbacher K.: Structure and morphology of baked starch foams. Polymer, 39, 6649-6655 (1998). DOI: $\underline{10.1016 / \mathrm{S} 0032-3861(97) 10303-2}$

[19] Glenn G. M., Orts W. J., Nobes G. A. R.: Starch, fiber and $\mathrm{CaCO}_{3}$ effects on the physical properties of foams made by a baking process. Industrial Crops and Products, 14, 201-212 (2001).

DOI: $\underline{10.1016 / \mathrm{S} 0926-6690(01) 00085-1}$

[20] Shogren R. L., Lawton J. W., Tiefenbacher K. F.: Baked starch foams: Starch modifications and additives improve process parameters, structure and properties. Industrial Crops and Products, 16, 69-79 (2002). DOI: $\underline{10.1016 / \mathrm{S} 0926-6690(02) 00010-9}$

[21] Lawton J. W., Shogren R. L., Tiefenbacher K. F.: Aspen fiber addition improves the mechanical properties of baked cornstarch foams. Industrial Crops and Products, 19, 41-48 (2004). DOI: $10.1016 / \mathrm{S} 0926-6690(03) 00079-7$

[22] Glasser W. G., Northey R. A., Schultz T. P.: Lignin: Historical, biological, and materials perspectives. American Chemical Society, Washington (2000).

[23] $\mathrm{Hu}$ T. Q.: Chemical modification, properties, and usage of lignin. Plenum Press, New York (2002).

[24] Kumar M. N. S., Mohanty A. K., Erickson L., Misra M.: Lignin and its applications with polymers. Journal of Biobased Materials and Bioenergy, 3, 1-24 (2009). DOI: $\underline{10.1166 / j b m b .2009 .1001}$

[25] Baumberger S.: Starch-lignin films. in 'Chemical modification, properties, and usage of lignin' (ed.: $\mathrm{Hu}$ T. Q.) Plenum Press, New York, 1-19 (2002). 
[26] Stevens E. S., Willett J. L., Shogren R. L.: Thermoplastic starch-kraft lignin-glycerol blends. Journal of Biobased Materials and Bioenergy, 1, 351-359 (2007).

[27] McCarthy J. L., Islam A.: Lignin chemistry, technology, and utilization: A brief history. in 'Lignin: Historical, biological, and materials perspectives' (eds.: Glasser W. G., Northey R. A., Schultz T. P.) American Chemical Society, Washington, 2-99 (2000).

[28] ASTM D 570: Standard test method for water absorption of plastics (2007).

[29] Abacha N., Kubouchi M., Sakai T.: Diffusion behavior of water in polyamide 6 organoclay nanocomposites. Express Polymer Letters, 3, 245-255 (2009). DOI: $10.3144 /$ expresspolymlett.2009.31

[30] Berketis K., Tzetzis D.: Long-term water immersion ageing characteristics of GFRP composites. Journal of Material Science, 44, 3578-3588 (2009).

DOI: $10.1007 / \mathrm{s} 10853-009-3485-9$

[31] ASTM D 790: Standard test methods for flexural properties of unreinforced and reinforced plastics and electrical insulating materials (2007).

[32] Shogren R. L., Jasberg B. K.: Aging properties of extruded high-amylose starch. Journal of Environmental Polymer Degradation, 2, 99-109 (1994). DOI: $10.1007 / \mathrm{BF} 02074778$

[33] Shogren R. L.: Effect of moisture content on the melting and subsequent physical aging of cornstarch. Carbohydrate Polymers, 19, 83-90 (1992). DOI: $\underline{10.1016 / 0144-8617(92) 90117-9}$
[34] Maaruf A. G., Che Man Y. B., Asbi B. A., Junainah A. H., Kennedy J. F.: Effect of water content on the gelatinisation temperature of sago starch. Carbohydrate Polymers, 46, 331-337 (2001). DOI: $\underline{\text { 10.1016/S0144-8617(00)00335-0 }}$

[35] Masaro L., Zhu X. X.: Physical models of diffusion for polymer solutions, gels and solids. Progress in Polymer Science, 24, 731-775 (1999). DOI: 10.1016/S0079-6700(99)00016-7

[36] Meinders M. B. J., von Vliet T.: Modeling water sorption dynamics of cellular solid food systems using free volume theory. Food Hydrocolloids, 23, 2234-2242 (2009). DOI: 10.1016/j.foodhyd.2009.05.007

[37] Crank J.: The mathematics of diffusion. Oxford University Press, New York (1975).

[38] Baumberger S., Lapierre C., Monties B., Della Valle G.: Use of kraft lignin as filler for starch films. Polymer Degradation and Stability, 59, 273-277 (1998).

[39] Shogren R. L., Lawton J. W., Teifenbacher K. F., Chen L.: Starch poly(vinyl alcohol) foamed articles prepared by a baking process. Journal of Applied Polymer Science, 68, 2129-2140 (1998).

DOI: $10.1002 /($ SICI $) 1097-4628(19980627) 68: 13$ $\leq 2129:$ :AID-APP9>3.0.CO;2-E

[40] Lawton J. W., Shogren R. L., Tiefenbacher K. F.: Effect of batter solids and starch type on the structure of baked starch foams. Cereal Chemistry, 76, 682-687 (1999). 